\title{
The Effect of Aluminium Content on the Bioactivity Behaviour of Magnesium Alloys for Biomedical Applications
}

\author{
Nur Maizatul Shima Adzali, ${ }^{1, *}$, Nur Hidayah Ahmad Zaidi ${ }^{1,2}$, and Mohd Ashraf Jamaludin ${ }^{1}$ \\ ${ }^{1}$ Schools of Materials Engineering, Universiti Malaysia Perlis, 01000, Kangar, Perlis, Malaysia. \\ ${ }^{2} \mathrm{CoE}$ Frontier Material Research Centre, Schools of Materials Engineering, Universiti Malaysia Perlis, 0100, Kangar, Perlis, Malaysia
}

\begin{abstract}
AZ series alloy which consist of aluminium $(\mathrm{Al})$ and zinc $(\mathrm{Zn})$ with magnesium $(\mathrm{Mg})$ as their base are the most investigated for biomedical applications among the $\mathrm{Mg}$ alloy. Al content plays a crucial part in differentiating the properties of Mg-based alloy for biomedical applications. Thus, this project picks up pure $\mathrm{Mg}$ and $\mathrm{AZ31}$ (with 3\% of $\mathrm{Al}$ ) alloy and the effect of $\mathrm{Al}$ content has been investigated. In this study, Mg alloy has been fabricated via powder metallurgy method in order to investigate its bioactivity behaviour. Bioactivity test of pure Mg and AZ31 alloys were conducted by immersing the samples in simulated body fluid (SBF) solution up to 6 hours to observe the formation of apatite layer on the sample surface. The bioactivity behaviour of the samples has been observed using scanning electron microscope (SEM) and X-Ray Diffraction (XRD) analysis. After bioactivity test, sample AZ31 showed the formation of more apatite layers compared to sample of pure $\mathrm{Mg}$ with the existence of new phases which were $\mathrm{Mg}(\mathrm{OH})_{2}$ and $\mathrm{MgO}$. This apatite layers might influence the ability of the Mg-based alloy to withstand the corrosive agent that will attack the alloy while being immersed in SBF.
\end{abstract}

\section{Introduction}

The implants in biomedical applications, most of them are metallic, are used in the human body mainly for orthopaedic purposes. Metallic materials play a very predominant role in fulfilling almost every difficult factor that arises in implant applications [1]. For example, stainless steels, Co-Cr-Mo alloys, $\mathrm{Ti}$ and $\mathrm{Ti}$ alloys and $\mathrm{Mg}$ and $\mathrm{Mg}$ alloys have been used in many biomedical applications. $\mathrm{Mg}$ and its alloys have tremendous mechanical properties that have made this metal and its alloy gained a wide popularity in implants applications. $\mathrm{Mg}$ and its alloy is one of the various metallic materials that are commonly used as biomedical devices. The main reason magnesium and its alloy were used because, their mechanical properties such as Young's modulus of elasticity, $\mathrm{E}=4-45 \mathrm{GPa}$ and density $=1.74-1.84 \mathrm{~g} / \mathrm{cm}^{3}$ are known to be similar that of bone $\left(\mathrm{E}=15-25 \mathrm{GPa}\right.$ and density $\left.=1.8-2.1 \mathrm{~g} / \mathrm{cm}^{3}\right)$. These properties were lower than other biodegradable materials such as iron-manganese (Fe-Mn) and zinc $(\mathrm{Zn})$ based alloys [2].

Aluminium considered as the most influencing element in aluminium and zinc (AZ) series magnesium alloys [3]. AZ series is as a series of aluminium and zinc content in the magnesium based composite. These series of alloy has been study widely to investigate its performance in the physiological condition. Two types of magnesium alloys, which were AZ31 and AZ91, with AZ91 marks the highest aluminium content with 9\%. Meanwhile, the lowest aluminium content goes to AZ31 which aluminium only contributed 3\%. All of these alloys contain $1 \%$ of zinc. Aluminium content affects the degradation rate of magnesium alloy implants. Lunder et al. (1989) witnessed that when aluminium content reaches $8 \%$ of mass fraction, the corrosion resistance of magnesium alloy improve in a visible level [4]. Warner et al. (1992) reported that even $5 \%$ addition of $\mathrm{Al}$ in magnesium alloys is useful in improving their corrosion resistance [5], while Hehmann et al. (1987) revealed that $9 \%$ and above $\mathrm{Al}$ is helpful in improving of corrosion resistance of magnesium alloy [6].

Formation of apatite layer is crucial and was given a top priority govern with the biomaterials implant. Apatite layer acts as a connector between the implant materials and living tissues. According to British Standards (BS), apatite means group of calciumphosphates including bone mineral and the main inorganic constituent of bones and teeth similar to hydroxyapatite, which has the composition $\mathrm{Ca}_{10}\left(\mathrm{PO}_{4}\right)_{6}(\mathrm{OH})_{2}$ [7]. Production of apatite layer can be done in the simulated body fluid (SBF) solution, with the solution must has an equal composition in term of blood plasma, and composition as well as structure of mineral bone. When implanted devices placed in human body, a thin layer of calcium and phosphorus forms on its surface before the material connects to the tissue through this apatite layer [7]. Formation of apatite layer is proportional to bioactivity, whereas it is increasing with increment in the rate of bioactivity behaviour.

In this study, pure Mg and AZ31 alloys have been fabricated via powder metallurgy method. Bioactivity

\footnotetext{
* Corresponding author: shima@unimap.edu.my
} 
test has been conducted to observe the formation of apatite layer on both sample surfaces. The bioactivity behaviour of the sample observed using SEM and XRD.

\section{Materials and Methods}

\subsection{Materials}

In this research, commercially available $\mathrm{Mg}, \mathrm{Al}$ and $\mathrm{Zn}$ powders were used as starting materials. For fabrication of AZ31 alloys powder, the mixing of $96 \%$ magnesium powders, $3 \%$ aluminium and $1 \%$ zinc powders were conducted by mixing and milling using roll mill. All these powders were supplied by the Merck Company. Figure 1 shows the SEM micrographs of Mg powders and AZ31 alloy powders.

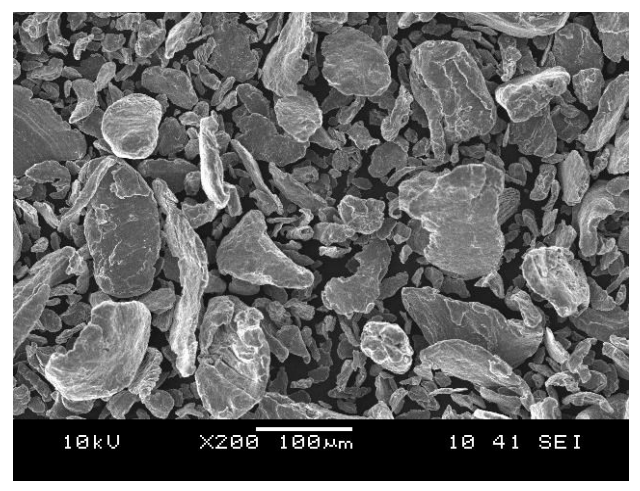

(a)

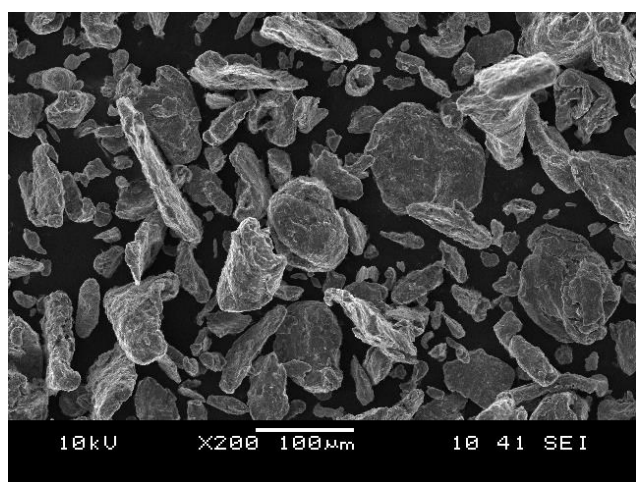

(b)

Figure 1. SEM micrographs of (a) Mg powders (b) AZ31 alloy powders.

\subsection{Methods}

\subsubsection{Powder Metallurgy}

The pure $\mathrm{Mg}$ and $\mathrm{Mg}$ based alloy samples (AZ31) were fabricated by blending, pressing and sintering, followed powder metallurgy route. The AZ31 alloy powder with 3 wt. $\%$ of $\mathrm{Al}$ particles was mixed in a rotary milling machine for 30 minutes at 130 RPM. The cylindrical green compacts of $13 \mathrm{~mm}$ in diameter and $14 \mathrm{~mm}$ in height were cold compacted under pressure of $500 \mathrm{MPa}$. The green samples were then sintered at $400^{\circ} \mathrm{C}$ for 2 hours in a tube furnace under argon atmosphere. Microstructures of the compacted samples were observed using a scanning electron microscope (SEM) (model JEOL, JSM-6420LA), equipped with energy dispersive spectrum (EDS). The sample was prepared by the standard metallographic methods of wet rotary grinding on a series of SiC papers, followed by polishing on the soft napped cloth (BUEHLER, USA). X-ray diffraction (XRD) was carried out on a Shimadzu (model XRD 6000), Japan radiation for phase analysis. The recorded spectrums were matched in accordance to the data from the JCPDF.

\subsubsection{Bioactivity Test}

To evaluate the bioactivity of sintered $\mathrm{Mg}$ and AZ31 alloy, the samples were immersed in a SBF according to the standard BS ISO 23317:2007 [7]. Table 1 shows the order of the reagents and weight of the reagents needed to prepare the SBF solution. The samples of $\mathrm{Mg}$ and AZ31 then were put in container which contain SBF before put in water bath for 6 hours with the starting $\mathrm{pH}$ and temperature of $\mathrm{SBF}$ were 7.4 and $36.5^{\circ} \mathrm{C}$ respectively. After 6 hours, the samples were gently cleaned with deionized water and dried at $37^{\circ} \mathrm{C}$ prior to analysis. After bioactivity test, SEM and XRD analyses were carried out in order to investigate the bioactivity behaviour of the samples.

Table 1. Reagent and amount to prepare 1L SBF solution.

\begin{tabular}{|c|c|c|}
\hline order & reagent & Amount (g) \\
\hline 1 & $\mathrm{NaCl}$ & 8.035 \\
\hline 2 & $\mathrm{NaHCO}_{3}$ & 0.355 \\
\hline 3 & $\mathrm{KCl}$ & 0.225 \\
\hline 4 & $\mathrm{~K}_{2} \mathrm{HPO}_{4} 3 \mathrm{H}_{2} \mathrm{O}$ & 0.231 \\
\hline 5 & $\mathrm{MgCl}_{2} \cdot 6 \mathrm{H}_{2} \mathrm{O}$ & 0.311 \\
\hline 6 & $\mathrm{c}(\mathrm{HCl})=1 \mathrm{~mol}^{\prime} \mathrm{l}$ & 39 \\
\hline 7 & $\mathrm{CaCl}_{2}$ & 0.292 \\
\hline 8 & $\mathrm{Na}_{2} \mathrm{SO}_{4}$ & 0.072 \\
\hline 9 & $\mathrm{TRIS}$ & 118 \\
\hline 10 & $\mathrm{c}(\mathrm{HCl})=1 \mathrm{~mol} / 1$ & 0 to 5 \\
\hline
\end{tabular}




\section{Results and discussions}

\subsection{SEM}

Figure 2 shows micrograph of SEM for pure $\mathrm{Mg}$ and AZ31 alloys after sintering at $400^{\circ} \mathrm{C}$ in tube furnace (before bioactivity test). In Figure 2 (a), it shows the microstructures of pure $\mathrm{Mg}$ with no addition of $\mathrm{Al}$ or $\mathrm{Zn}$. The EDS spectrum only shows the presence of $\mathrm{Mg}$ element in the samples. In Figure 2 (b), the micrographs revealed the microstructure of AZ31 (magnesium based alloys with $3 \%$ of $\mathrm{Al}$ and $1 \%$ of $\mathrm{Zn}$ ) with EDS spectrums shows the presence of $\mathrm{Mg}, \mathrm{Al}$ and $\mathrm{Zn}$ elements. Figure 2 (b) shows there is a presence of pores on the sample surface compared with Figure 2 (a) which have flat surface with no pores.
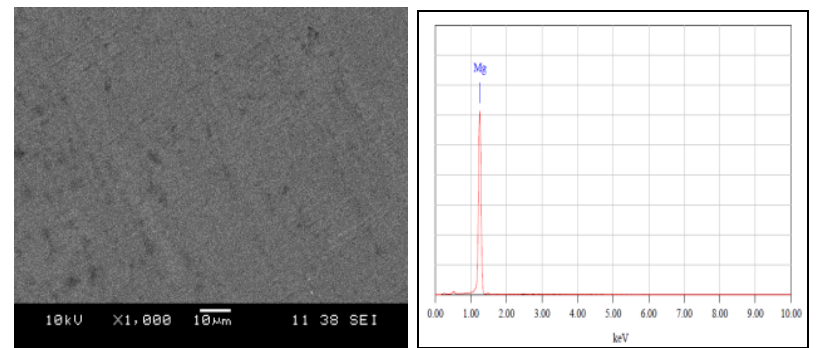

(a)
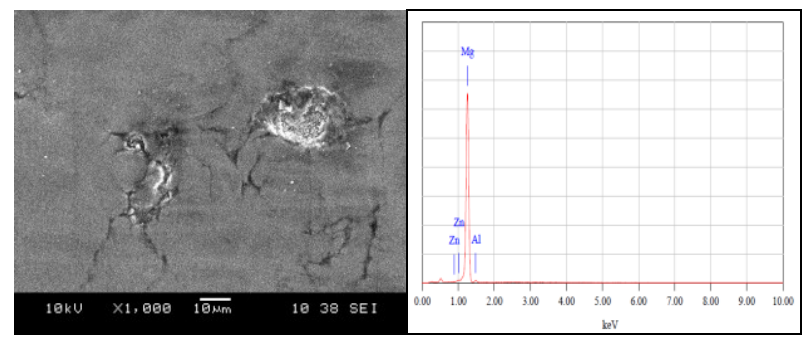

(b)

Figure 2. SEM and EDS results of (a) $\mathrm{Mg}$ (b) AZ31 after sintering at $400^{\circ} \mathrm{C}$ (before immersion test).

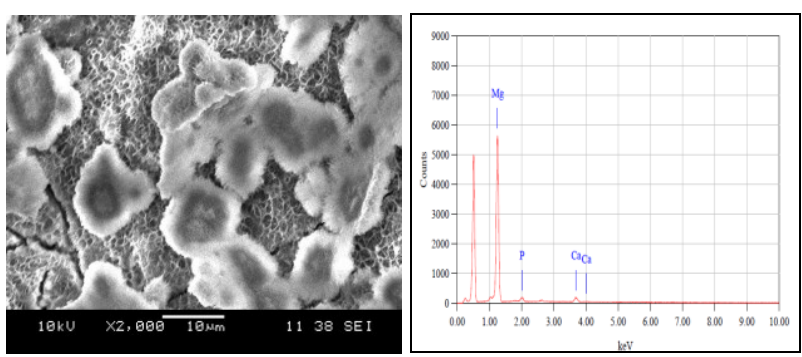

(a)

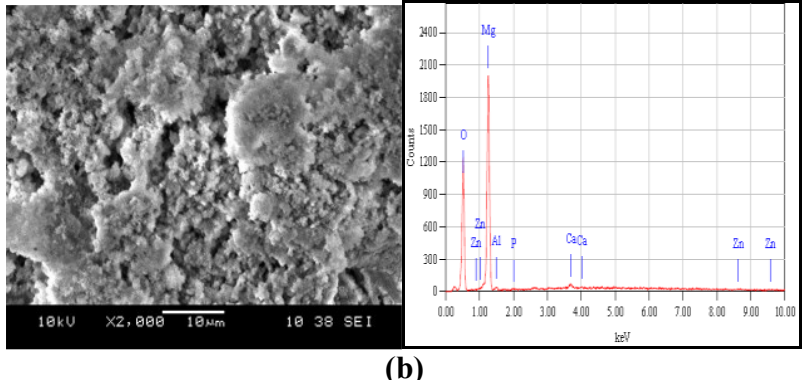

(b)

Figure 3. SEM and EDS results of (a) Mg (b) AZ31 after bioactivity test.

Figure 3 shows the microstructures of the sintered samples surface after immersion in the SBF up to 6 hours. Figure 3 (a) shows that the sample without addition of $\mathrm{Al}$ (pure $\mathrm{Mg}$ ) exhibited the formation of apatite layer with white particles/granular on the corroded surfaces and grain boundaries. A small amount of $\mathrm{Ca}$ and $\mathrm{P}$ element (from SBF) is detected from EDS results. For samples with addition of $\mathrm{Al}$ and $\mathrm{Zn}$ (AZ31), Figure 3 (b) shows, the formation of many white particles. These white particles covered the entire sample surface with no grain boundary can be seen. It's revealed that more white particles (spherical shape) precipitated on the surface of the samples as more alloying elements are added; most pores are invisible due to the coverage of the newly formed deposition. The EDS result (Figure $3 \mathrm{~b}$ ) indicates that the precipitate layer composed of small amount of calcium (Ca), and phosphorus $(\mathrm{P}), \mathrm{Mg}, \mathrm{Al}, \mathrm{Zn}$ and $\mathrm{O}$. This result indicates that as alloying elements are added to pure $\mathrm{Mg}$, the presence of apatite layer is obvious compared to pure $\mathrm{Mg}$. This result is in agreement with Shamsul et al. (2014) which studied about the addition of filler (HAP) to metal (Co-Cr-Mo). They found that as more HAP is added to $\mathrm{Co}-\mathrm{Cr}-\mathrm{Mo}$, the formation of apatite layer on the sample surface was increased and covered the entire sample surfaces [8].

From the previous findings, the formation of apatite particles and transformation into the apatite layer as more alloying elements is added can be divided into two stages: nucleus formation and nucleus growth [9-10]. Certainly, the nature and crystallinity of apatite phase phases depend on various parameters, including concentrations of phosphate/carbonate sources, ionic strength and $\mathrm{pH}$ of the soaked solution, and the kinetics of the nucleation and growth processes [11]. In general, the formation mechanism of apatite is dissolutionprecipitation reaction. 


\subsection{XRD}

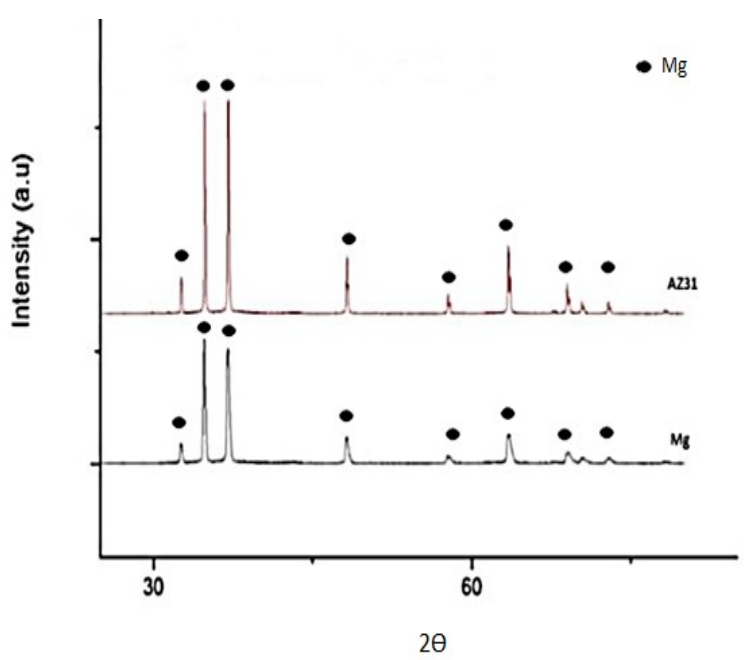

Figure 4. XRD result of $\mathrm{Mg}$ and $\mathrm{AZ31}$ before bioactivity.

Figure 4 shows the XRD patterns of the surface of the sintered samples $\mathrm{Mg}$ and AZ31before bioactivity. $\alpha \mathrm{Mg}$ gives the most peaks for both sample. $\alpha \mathrm{Mg}$ (PDF No.: 03-065-4596) peak located at $35^{\circ}, 37^{\circ}, 48^{\circ}, 53^{\circ}$ and $69^{\circ}$, $71^{\circ}$ and $74^{\circ}$.

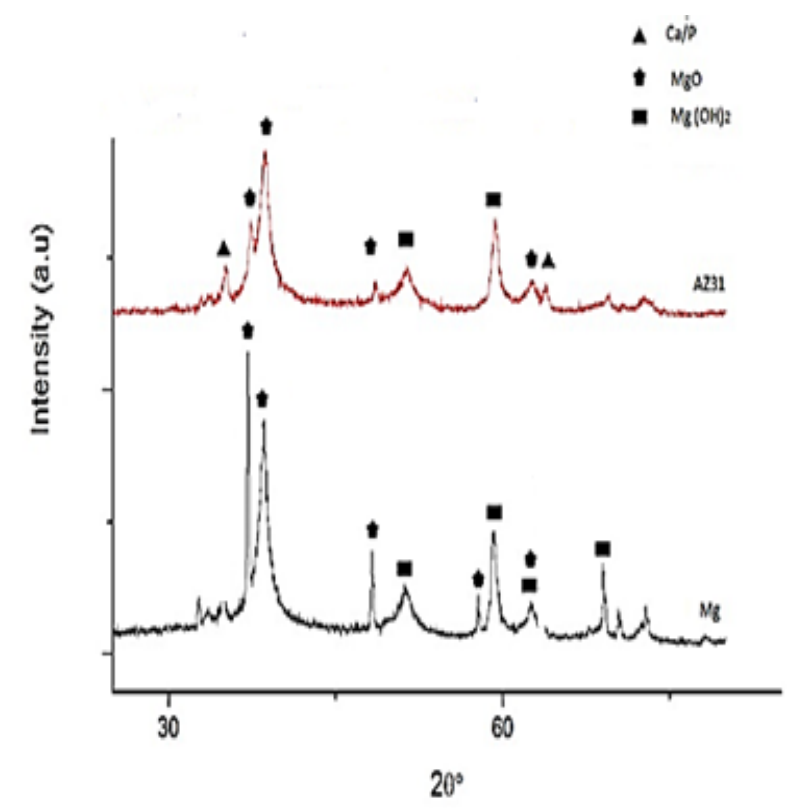

Figure 5. XRD result of $\mathrm{Mg}$ and $\mathrm{AZ31}$ after bioactivity.

Figure 5 shows the XRD patterns of $\mathrm{Mg}$ and AZ31 after undergo bioactivity test. The test was conducted by immersion samples in SBF for six hours. As shown from the patterns, new phases exist after bioactivity test which were $\mathrm{Ca}, \mathrm{P}, \mathrm{MgO}$ and $\mathrm{Mg}(\mathrm{OH})_{2}$. Ca P phase has its peak existed at the AZ31 sample. MgO (PDF No.: 00-0021207) phase which may be found in both samples was the result of corrosion products. $\mathrm{MgO}$ peak was observed at $37^{\circ}, 42^{\circ}$ and $63^{\circ}$. Reaction between the $\mathrm{OH}-$ ions in
SBF with both sample resulting in formation of $\mathrm{Mg}(\mathrm{OH})_{2}$ (PDF No.: 01-086-0441) at 51 $1^{\circ}, 59^{\circ}$ and $69^{\circ}$. There is a literature reports that $\mathrm{Mg}(\mathrm{OH})_{2}$ peak intensity will increase if the immersion time in the SBF longer [12].

The present result is also in agreement with Razavi et al. (2010) who conducted the research about $\mathrm{Mg}$ /Fluoroapatite (FA). They found that immersion of $\mathrm{Mg} / \mathrm{FA}$ composite in SBF for $72 \mathrm{~h}$ shows the formation of white particles of cauliflower shape on the entire surface of $\mathrm{Mg} / \mathrm{FA}$ sample compared to samples with no FA. XRD presents after bioactivity, a new phase which detected as $\mathrm{Mg}_{17} \mathrm{Al}_{12}$ [13].

\section{Conclusions}

This research is conducted to shows the effects of $\mathrm{Al}$ contents to the bioactivity behaviour of $\mathrm{Mg}$ based alloys. From the results, it shows that it is possible to bioactivate the surface of pure $\mathrm{Mg}$ with the addition of $\mathrm{Al}$ and $\mathrm{Zn}$ to produce apatite layer on the $\mathrm{Mg}$ alloy surface. This apatite layer formation considered as the mark of bioactivity. Based on SEM microstructure, its shows the numerous growth of apatite cluster by the additions of $\mathrm{Al}$ in $\mathrm{Mg}$ based alloys. The result showed that formation of apatite layer increases as the alloying elements is added with the formation of new phases which were $\mathrm{Ca}, \mathrm{P}, \mathrm{MgO}$ and $\mathrm{Mg}(\mathrm{OH})_{2}$. Thus, we conclude that this AZ31 alloys can be good alternative materials for biomedical application.

This work is financially supported from FRGS grant (900300367) by MOHE Malaysia.

\section{References}

1. U. Kamachimudali, T. M. Sridhar, Baldev Raj, Sadhana 28, 601-637 (2003).

2. S. Agarwal, J. Curtin, J., B. Duffy, \& S. Jaiswal, Materials Science and Engineering: C 68, 948-963 (2016).

3. A. R. Bharat, B. S. S. Kumar, R. P. Sarath, P. Akhil, G. P. K. Reddy, \& B. R. Sunil, Journal of Advances in Biomedical Engineering and Technology 2, 17-23 (2015).

4. O. Lunder, J. E. Lein, T. K. Aune, \& K. Nisancioglu, Corrosion 45(9) 741-748 (1989).

5. T.J. Warner, N. Thorne, G. Anussbaum, \& W.M. Stobbs, J. Surf. Int. Ana. 19 386-392 (1992).

6. F. Hehmann, F. H. Froes, \& W. Young, Journal of Metals 39(8) 14-21 (1987). 
7. British Standard. Implants for surgery - In vitro evaluation for apatite-forming ability of implant materials, BS ISO 23317:2007 (2009).

8. Shamsul Baharin Jamaludin, Nur Maizatul Shima Adzali, \& Mohd Nazree Derman, Acta Metallurgica Slovaca 20, 82-88 (2014).

9. D. Cortes, A. Medina, S. Escobedo, \& M. A. Lopez, Journal of Materials Science 40 3509-3515 (2005).

10. Y. P. Guo, Y. Zhou, D. C. Jia, C. Q. Ning, \& Y. J. Guo, Materials Science and Engineering C 30 472479 (2010).

11. C. Wu, \& J. Chang, Materials Letters 61 2502-2505 (2007)

12. D. Gopi, P. R. Bhalaji, S. Ramya, \& L. Kavitha, Journal of Industrial and Engineering Chemistry 23 218-227 (2015).

13. M. Razavi, M.H. Fathi, \& M. Meratian, Materials Characterization 61 1363-1370 (2010). 